\title{
As narrativas históricas comparadas sobre a Questão do Amapá
}

\section{Comparative Historical Narratives on the Question of Amapá}

\author{
Danilo Sorato Oliveira Moreira*
}

\section{Resumo}

$\mathrm{O}$ artigo tem por objetivo apresentar as narrativas históricas comparadas sobre a Questão do Amapá em suportes acadêmicos e didáticos. A metodologia pauta-se no método comparativo em história, o qual analisa as possibilidades de características das linguagens históricas. A hipótese é que as narrativas históricas podem apresentar as características de arquétipo, estereótipo, silêncio e esquecimento. O resultado é que as narrativas acadêmicas negam a hipótese, pois elas revelam a preocupação em valorizar personagens históricos marginalizados, silenciados e esquecidos pela historiografia anterior ao século XXI. As narrativas didáticas, entretanto, subdivididas em livros didáticos e paradidáticos, confirmam a hipótese inicial, porquanto se caracterizam pela aceitabilidade de arquétipo, estereótipo, silêncio e esquecimento. A conclusão é que as narrativas históricas comparadas são heterodoxas, diversas e plurais, possibilitando a utilização de diferentes linguagens históricas no Ensino de História. Palavras-chave: ensino de história; narrativas históricas; Questão do Amapá.

\begin{abstract}
The article aims to present the historical narratives compared on the Question of Amapá in academic and didactic supports. The methodology is based on the comparative method in History, which analyzes the possibilities of characteristics of the historical languages. The hypothesis is that historical narratives may present the characteristics of archetype, stereotype, silence, and forgetfulness. The result is that the academic narratives deny the hypothesis, since they reveal the concern to value historical personages marginalized, silenced and forgotten by the historiography before the 21 st century. Nevertheless, the didactic narratives, subdivided in textbooks and supplementary educational books, confirm the initial hypothesis, because they are characterized by the acceptability of the archetype, stereotype, silence and forgetfulness. The conclusion is that the comparative historical narratives are heterodox, diverse and plural, making possible the use of different historical languages in History Teaching.
\end{abstract}

Keywords: teaching History; historical narratives; Question of Amapá.

\footnotetext{
* Mestre em Ensino de História pela Universidade Federal do Amapá (UFAP), Macapá, AP, Brasil. danilosorato@hotmail.com
} 
A narrativa é um elemento primordial no conhecimento histórico, especialmente quando se faz a transposição didática para o espaço escolar. ${ }^{1}$ Nesse exercício, o professor de história necessita compreender quais características determinado evento histórico vem apresentado nos suportes utilizados em sala de aula, para que consiga tornar a aprendizagem em história significativa para o aluno.

No início do século XXI, o autor Jörn Rüsen empreendeu esforços em gerar uma relação profícua entre os estudos de consciência histórica e a narrativa histórica. Segundo Rüsen (2011, p. 79), a aprendizagem histórica torna-se real para o aluno quando este consegue articular as três dimensões em torno da narrativa histórica: a experiência, a interpretação e a orientação. A experiência histórica

é a diferença qualitativa entre o passado e o presente. A aprendizagem histórica está preocupada com o fato de que o passado é um tempo qualitativamente diferente do presente e se tornou o tempo presente. A experiência histórica é, portanto, principalmente a experiência da diferença no tempo. (Rüsen, 2011, p. 85)

Dessa forma pode-se afirmar que ela se revela no momento em que o aluno demonstra estar apto para perceber as diferenças entre o tempo passado e o presente com base em seu conhecimento prévio do assunto proposto - no nosso exemplo, a Questão do Amapá.

As origens da Questão do Amapá estão ligadas às Grandes Navegações, quando os países europeus iniciaram uma disputa acirrada pelas terras do Novo Mundo. Pelas condições geográficas, políticas e econômicas, Portugal e Espanha começaram a ocupação das terras americanas no século XV. Essa assertiva é corroborada com a assinatura do Tratado de Tordesilhas, que:

dividiu o futuro Novo Mundo em 1494, sem saber, na altura da foz do Amazonas (Doc. 1). No Oeste, a região das Guianas entre Orinoco e Amazonas encontrava-se na parte atribuída aos espanhóis, só que esses, mais interessados pelas riquezas do México e do Peru, desprezaram essa terra cujo litoral era inóspito demais. Os portugueses, conformando-se a esta bula papal, não ultrapassaram o Amazonas quando descobriram e começaram a explorar o Brasil a partir de 1500. (Granger, 2012, p. 22) 
Discordando dessa divisão, a França iniciou uma série de invasões nas colônias portuguesa e espanhola na América nos séculos XV, XVI e XVII, a fim de conquistar tanto a região das Guianas quanto o Nordeste brasileiro. Os franceses tentaram se estabelecer no Rio de Janeiro (França Antártica), em seguida no Maranhão (França Equinocial), e finalmente, procuraram se fixar nas Guianas. Após o insucesso nas duas primeiras invasões, os franceses conseguiram manter contato direto com a região do Oiapoque. Segundo os historiadores Jonathan Viana e Diovani Silva (2012, p. 43), a partir de 1679 se iniciam as tensões entre portugueses e franceses pela posse desse território, visão corroborada por Francinete Cardoso (2008, p. 14), que aponta as incursões dos franceses no século anterior na região entre Orénoque e a boca do Amazonas, o que efetivou a colonização da Guiana Francesa. Pode-se também verificar a colonização europeia no Amapá pela presença holandesa no século XVII, como defendem Hulsman e Guzmán (2011, p. 180) nas incursões de Jan Swaerooch, que viajou três vezes para o Extremo Norte do Brasil a fim de fazer comércio com os indígenas locais. Esse exemplo demonstra que não apenas os franceses tinham fins políticos, econômicos, territoriais ou religiosos, mas também os holandeses e ingleses. Estes últimos, aliás, são responsáveis pela exploração ampliada do Platô das Guianas, especificamente ao chegarem à Guiana inglesa e ao Suriname.

\section{O MÉTODO COMPARATIVO NO ENSINO DE HISTÓRIA}

A metodologia desta pesquisa se baseia no método comparativo em história, o qual percebe como as narrativas históricas nos suportes citados se comportam. Essa estratégia metodológica em história pretende colaborar com o desenvolvimento das habilidades e competências (gerais e específicas) pedidas nos documentos oficiais sobre educação, em especial na terceira - e espera-se - última versão da Base Nacional Comum Curricular (BNCC). Esse documento ressalta a importância dos professores de história para o Ensino Fundamental, assim como pede que o aluno seja habilitado pelo docente em dois momentos; por um lado, de maneira geral, pede-se que o discente consiga ser capaz de fazer a comparação em história (Brasil, 2017, p. 348), ou seja, ele precisa se apropriar das semelhanças e diferenças entre momentos históricos diferentes, como por exemplo, perceber o que se alterou o permaneceu nos diversos tempos históricos da 
República Brasileira; por outro lado, de forma específica, espera-se que o discente consiga comparar processos históricos, mecanismos de ruptura e transformações sociais, políticas, econômicas e culturais (Brasil, 2017, p. 352). Nesse sentido, opta-se pelo método comparativo, como dizem Schneider e Schmitt (1998, p. 1), com a finalidade de buscar regularidades, perceber os deslocamentos e mudanças, construir modelos e tipologias.

A definição dos autores em relação à busca por aquilo que é regular, deslocado e transformado pela construção de modelos e tipologias, pela percepção do que se mantém e do que não se mantém, as similitudes e diferenças, é aspecto primordial na análise dos diversos suportes sobre as narrativas históricas da Questão do Amapá, com o objetivo de apresentar as diversas opções históricas presentes nessas obras. Assim, os professores de História são levados a utilizar um número significativo de interpretações em suas aulas. A busca pelo que permanece e pelo que se modifica nos discursos escritos sobre o tema histórico estabelece as características próprias de cada narrativa histórica. Algumas narrativas revelam-se carregadas de arquétipo, estereótipo, silêncio e esquecimento.

Os suportes didáticos analisados neste artigo refletem silêncio e esquecimento, sobretudo os livros trabalhados em sala, como Santos (2001), Magalhães e Hermeto (2015), Azevedo e Seriacopi (2013) e Moraes e Oliva (2017). Outras narrativas históricas mostram-se distantes dessas premissas teóricas, como os suportes acadêmicos analisados nesta pesquisa que pretendem mostrar os personagens históricos esquecidos, marginalizados e silenciados, tal como Queiroz (2001), Alves (2015; 2017) e Viana e Silva (2012).

O método comparativo em história, na visão das autoras Neyde Theml e Regina Bustamante (2007, p. 3), pode ser entendido com base nas ideias defendidas pelo historiador francês Marc Bloch, desenvolvidas nos anos 1930. Segundo ele, a comparação em história possibilitava maior conhecimento das sociedades em seus aspectos diacrônicos e sincrônicos, ou seja, permitia pesquisar e entender questões específicas e gerais sobre os fenômenos para então entender as suas causas e origens. Com o desenvolvimento do campo de estudos da história comparada, na segunda metade do século XX, Marcel Detienne (2000, p. 59) expande a sua perspectiva sobre o método comparativo procurando ampliar seu foco de análise através dos tempos presente e passado, assim como ampliar a comparação entre sociedades diferentes. 
O Ensino de História reúne uma vasta bibliografia acerca de outros temas para além das narrativas históricas. Como suporte desta pesquisa, o livro didático é importante fonte de informação. Segundo Bittencourt (2004, p. 69), a linguagem no ensino de história é percebida por meio de gravuras, imagens, fotos, filmes, mapas e textos - signos de representação acerca dos diversos conteúdos históricos curriculares. O livro didático, como uma das fontes de informação mais utilizadas e instrumento desta pesquisa, reflete diversas concepções, inclusive daquelas pessoas que os produzem - as editoras. Pelo seu uso cotidiano em sala de aula, a análise das narrativas históricas contidas nesses suportes se torna crucial, como demonstrado em Magalhães e Hermeto (2015), Moraes e Oliva (2017), Azevedo e Seriacopi (2013).

Entretanto, entende-se que a análise das narrativas históricas deve ser levada para outros suportes, como os acadêmicos, em Queiroz (2001), Viana e Silva (2012) e Alves (2015; 2017). Essa ampliação de suportes permite identificar as suas respectivas características selecionadas através do arquétipo, estereótipo, silêncio e esquecimento. Portanto, essa leitura e a posterior comparação entre os suportes como estratégia didática no ensino de história, na proposição de Zaslavsky (2010), pode fazer os efeitos dessa linguagem serem mapeados. Em verdade, o professor de História, ao contar com essa pluralidade de narrações sobre a Questão do Amapá, tem como apontar para seus alunos novos olhares e confrontos entre os autores que propõem selecionar alguns caminhos. Logo, faz-se necessária uma breve discussão conceitual sobre arquétipo, estereótipo, silêncio e esquecimento, para que se possa apresentar as narrativas acadêmicas e didáticas.

O Arquétipo é um conceito-chave importante para entender as narrativas históricas por meio do debate acerca da psicologia humana pela valorização de heróis, deuses e o sobrenatural - capacidade psicológica que se encontra em produções como os livros e narrativas históricas. Na Questão do Amapá, alguns personagens históricos como o barão do Rio Branco e Cabralzinho são alçados a essa condição arquetípica ao longo do tempo. Portanto, a utilização do arquétipo para comparar os diversos textos acadêmicos e didáticos permite mapear quais autores e suas narrativas históricas se enquadram no formato de valorizar heróis e deuses.

A obra de Carl Jung é fundamental para a compreensão de Arquétipo e do inconsciente coletivo. Na busca pela melhor conceituação de Arquétipo, 
faz-se uma correlação entre o vocábulo e o mito (Jung, 2000, p. 18). O mito junguiano, em sua ligação com os fenômenos da natureza, tais como o sol e a lua, apresenta-se como um modelo inconsciente que a humanidade primitiva projetou na explicação dos eventos naturais. Nesse escopo, a humanidade contemporânea, ainda que baseada na ideia de razão e de progresso, utiliza-se de arquétipos mitológicos para a construção de projetos estatais, especificamente no momento de ruptura dos regimes de historicidade, como diz Hartog (2014, p. 23), quando se forjam novos tempos, governos, símbolos, heróis e mitos. O Brasil, entre 1885 a 1902, passa por esse processo com a ampliação da crise imperial e o início da Primeira República. O governo republicano buscou forjar heróis que representassem o seu ideal, procurando projetar na consciência coletiva nacional diversas figuras do passado e do presente brasileiros, tais como Tiradentes e o barão do Rio Branco. Esses personagens são utilizados em narrativas históricas que visam torná-los seres alienígenas ao corpo social brasileiro, isto é, homens dotados de uma capacidade de solucionar os fenômenos sociais considerados sem solução - somente as habilidades mitologizadas desses heróis tornam possível a conclusão de eventos históricos, como a Questão do Amapá. ${ }^{2}$

O Estereótipo é conceito-chave fundamental para a significação de algumas narrativas históricas nesta pesquisa, pois, assim como o Arquétipo, pode ser percebido em narrativas históricas que omitem a participação de outros personagens históricos na Questão do Amapá, como é o caso de Queiroz (2001), Viana e Silva (2012) e Alves (2015; 2017), os quais não mostram como indígenas, negros e garimpeiros, dentre outros, também participam nesse cenário de litígio entre Brasil e França.

No início do século XXI, em artigo publicado sobre as noções de Estereótipo na imagem do Brasil no exterior, os autores Danilo Brito e Fabiano Bona definiram o termo como "um 'tipo social', uma representação comum posta em larga circulação, mas que não necessariamente faz jus à realidade: ela existe somente enquanto representação social de um dado real" (Brito; Bona, 2014, p. 18). Os autores articulam o conceito com as representações sociais imaginadas por determinada sociedade, e em seu texto se referem aos comunistas nos Estados Unidos da América. Apesar da distância temporal entre o fenômeno explicado na década de 1960 sobre o comunismo e a Questão do 
Amapá nos anos 1900, é possível utilizar a ideia de "tipo social” criada pelos discursos, como as narrativas históricas.

Duas questões são fundamentais: em primeiro lugar, a ideia de estereotipar enquanto exercício de afirmar a si próprio e ao seu grupo social, serve como base para entender por que narrativas históricas exaltam alguns personagens - como o barão do Rio Branco ou Cabralzinho -, já que estes pertencem a uma categoria social própria, um como representante e patrono dos diplomatas, o outro como representante e patrono da polícia militar do Amapá. O segundo aspecto consiste em perceber que este trabalho se diferencia dos demais por não estudar os fenômenos do Estereótipo sob a luz do racismo e da xenofobia, algo corrente nos trabalhos de Educação e Ensino de História, como defendem Ramos, Licori e Utzig (2015), mas sim pretende revelar o Estereótipo como uma característica possível em narrativas históricas sobre a Questão do Amapá com forte sentido de pertencimento a um grupo social.

Tais argumentos são encontrados nos livros didáticos pesquisados como Moraes e Oliva (2017), Magalhães e Hermeto (2015) e Azevedo e Seriacopi (2013). Eles foram trabalhados entre os anos de 2013 e 2017 em um município adjacente a Macapá, chamado Santana. Na Escola Madre Tereza, os suportes didáticos não mencionavam a Questão do Amapá entre os conteúdos relacionados à Primeira República. Portanto, os processos de estereótipo, silêncio e esquecimento estão presentes nessas narrativas históricas e linguagens normalmente marcadas pela justificativa de trabalhar a história nacional, como aponta o próprio texto introdutório dos livros em Moraes e Oliva (2017, p. 3) e Magalhães e Hermeto (2015, p. 5).

O Silêncio e o Esquecimento são categorias-chaves na análise das narrativas históricas nesta pesquisa, pois se entende que tais estudos embasam a utilização dessa característica em suportes didáticos, sobretudo nos livros de Moraes e Oliva (2017), Magalhães e Hermeto (2015), Azevedo e Seriacopi (2013), onde não há nenhuma referência à Questão do Amapá.

O termo Silêncio é classicamente trabalhado na historiografia pelo autor Michael Pollak. Em suas análises acerca do que seria o Silêncio, o pesquisador ressalta a interligação com os campos da Memória e do Esquecimento. Pollak (1989, p. 4) afirma que esses conceitos florescem na sociedade especificamente em momentos de tensões sociais, quando se revelam as lutas, os conflitos e as disputas pela Memória. Em torno dessas pelejas sociais é que o Silêncio 
aparece como fruto de oposição aos discursos oficiais. Há aquilo que os Estados nacionais desejam revelar e o que desejam esquecer/silenciar - na definição de Pollak (1989, p. 8), as memórias coletivas oficiais e subterrâneas.

Nas disputas entre essas duas memórias aparece o silêncio. $\mathrm{O}$ ato de esquecer fatos e acontecimentos históricos de forma proposital, na visão de Pollak, reflete uma deliberação consciente e intencional. Vale ressaltar que o autor fala em memória coletiva a partir de outra noção, no caso, o enquadramento. Apesar dessa colocação, é necessário perceber como Pollak $(1989$, p. 9) define as funcionalidades da Memória afirmando que ela pode gerar elementos de coesão nas coletividades - como a família, aldeias, regiões etc.

O termo Esquecimento é utilizado por Paul Ricoeur (2007, p. 424) para afirmar que a memória é uma espécie de acidente mental: entre os diversos fragmentos factuais impossíveis de serem armazenados no cérebro humano existe uma luta, um conflito entre a Memória e o Esquecimento. Diz Ricoeur (2007, p. 455) que o esquecimento é um processo seletivo na narrativa, pois, quando se escolhe um caminho, esquece-se outro. Ele define que o processo de narração da história possui estratégias de esquecimento, ou seja, coloca-se o foco em alguns protagonistas e acontecimentos.

Essa ideia é o ponto capital da pesquisa sobre as narrativas históricas comparadas em relação à Questão do Amapá. A percepção de que toda narrativa histórica tem uma seleção de informações, fatos e personagens que levam ao clímax e à conclusão demonstra que os suportes escolhidos (didáticos e acadêmicos) nesta pesquisa, ainda que apresentem grande quantidade de fontes sobre o fenômeno histórico, não conseguem dar conta de toda a trama que envolve o acontecimento histórico analisado, porque - como diz Ricoeur - é impossível a ideia de narração exaustiva, não se pode falar de tudo nem se guardarem todas as memórias sobre o evento.

Outro aspecto importante surge quando se focaliza a Memória manipulada apenas pelas narrativas oficiais. No exemplo específico de Ricoeur, aponta-se a relação do Estado francês na construção das narrativas após a Segunda Guerra Mundial (1939-1945). Entende-se que as instituições oficiais apresentam uma capilaridade ao entorno da construção da memória coletiva muito mais abrangente que outros espaços, como a academia e o espaço escolar. Porém, negar que estes dois últimos espaços consigam manipular a Memória é um exercício extremamente perigoso. Ao longo da história brasileira, já 
tivemos momentos em que os intelectuais se articularam com as instituições oficiais em busca de uma memória coletiva manipulada. No período imperial, por exemplo, é celebre o interesse dos intelectuais ancorados pelo capital e pela vontade do imperador, Pedro II, em criar uma memória que fundasse o Estado brasileiro a partir da segunda metade do século XIX, como diz Schwarcz (1998). É fundamental lembrar que nesse caso, os intelectuais não agiam de modo organizado em espaços acadêmicos ou escolares, mas de forma individualizada, e produziam para públicos com perfil dessa natureza. Um dos fundadores da nossa historiografia, Adolfo Varnhagen, além de atuar na maior instituição que produzia conhecimento histórico no Brasil, o Instituto Histórico e Geográfico Brasileiro (IHGB), também ministrava aulas em espaços escolares, como o Colégio Pedro II.

\section{As NARRATIVAS HISTÓRICAS E ACADÊMICAS}

O pesquisador Jonas Marçal Queiroz disserta acerca do povoamento na Amazônia pelos quilombolas e republicanos entre os séculos XVIII e XIX. Em sua narrativa histórica acadêmica, o autor pretende problematizar a Questão do Amapá:

Mas afinal, quais seriam as relações entre tais episódios e a formação de quilombos nas fronteiras entre o Brasil e Guiana Francesa? Em que medida os conflitos de natureza político-ideológica, envolvendo lideranças do estado do Pará e da Capital Federal, podem ter contribuído para a criação e difusão do mito Cabralzinho? Até que ponto as fronteiras do país foram envolvidas no processo de mobilização simbólica em torno da constituição do imaginário da República? (Queiroz, 2001, p. 126)

A preocupação desse pesquisador, portanto, é fazer uma conexão entre os acontecimentos de finais do século XIX na região entre o Oiapoque e o Araguari, levar em consideração a figura do herói local Veiga Cabral (Cabralzinho) e, ao mesmo tempo, compreender de que maneira os quilombos de negros se formavam na região de fronteiras. Na sua justificativa em analisar os grupos sociais relegados ao Esquecimento, no caso dos quilombolas, o autor não pretende utilizar a visão da historiografia que mostrava o quilombo como 
um elemento contracultural e distante da sociedade que o cercava, mas sim apresentar a República dos quilombolas na região do litígio franco-brasileiro sob a ótica de que eles estabeleciam relações comerciais com a sociedade do Oiapoque e do Araguari, com vistas a sua própria sobrevivência em termos de gêneros alimentícios (Queiroz, 2001, p. 127). Sua opção pela narrativa histórica acadêmica que apresenta grupos sociais marginalizados revela que o autor tenta evitar a divulgação de uma imagem estereotipada sobre a Questão do Amapá e pretende, ao invés de exaltar as classes sociais ligadas às instituições oficiais republicanas, como diplomatas e militares, revelar a importância das pessoas que viviam o cotidiano do território em litígio. Além disso, Queiroz busca demonstrar o papel de Veiga Cabral na Questão do Amapá, entre o seu papel mitológico e real. O autor deixa de elevar a figura de Cabral de forma heroica quando diz:

As tentativas de transformar Veiga Cabral em herói nacional não foram bem-sucedidas, como de resto frustrou-se o empenho dos republicanos em recriar o imaginário popular, moldando-o de acordo com os princípios e valores republicanos. Um ex-monarquista, que pegara em armas para impedir a posse de uma das principais lideranças regionais da jovem República, foi recebido pelo presidente Prudente de Morais, homenageado por figuras ilustres como José do Patrocínio e Olavo Bilac, e esquecido assim que o litígio com a França foi resolvido. A República brasileira nunca foi capaz de conviver com as massas, pois jamais conseguiu transcender o âmbito restrito das elites que a criaram e atingir a mente e o coração dos cidadãos. (Queiroz, 2001, p. 155)

A definição de Queiroz sobre o papel de Veiga Cabral na Questão do Amapá apresenta uma faceta pouco revelada desse personagem histórico em instituições oficiais na cidade de Macapá, onde se exalta a sua participação no litígio franco-brasileiro mediante homenagens com bustos e nomes de ruas, estabelecimentos e praças. A sua narrativa histórica acadêmica não apresenta a característica de Arquétipo, no qual as imagens do mito e do herói se confundem em prol da construção de personagens históricos que forjem a Primeira República (1889-1930).

Outra narrativa histórica acadêmica, de Jonathan Viana e Diovani Silva, traz este objetivo: 
Tivemos como objetivo refletir sobre o processo histórico de transformação de Francisco Xavier da Veiga Cabral, o "Cabralzinho", em herói, organizando e sistematizando as ideias a respeito do ocorrido e seu "feito" na Vila do Espírito Santo do Amapá, em que se analisou a construção do imaginário popular dentro da área do ex-Contestado franco-brasileiro, compreendeu-se como e para que se constrói um herói na sociedade, e discutiu-se a sua resistência a tantas críticas e ao tempo. (Viana; Silva, 2012, p. 38)

Essa análise se insere na tentativa de compreender a construção da figura de Veiga Cabral como herói na sociedade amapaense. A opção narrativa se conecta de maneira crítica com o rechaço a características arquetipadas que estiveram presentes em boa parte de estudos sobre o tema. O objetivo do livro se agrega à problemática "O Povo amapaense considera ainda Cabralzinho Herói do Amapá?” (Viana; Silva, 2012, p. 38), pois busca analisar as diversas opções de respostas, positivas ou negativas, sobre a possível heroicização de Cabralzinho na sociedade local. Essa versão narrativa se confirma quando afirmam:

Veiga Cabral é reconhecido pelo Governo brasileiro como herói nacional, concedendo-lhe o Presidente da República o título "General honorário" do Exército Brasileiro. Assim, Francisco Xavier da Veiga Cabral conseguira conquistar a admiração de muitos homens e mulheres do Brasil. [...] Estava definido que Cabralzinho fora o homem responsável por defender o povo brasileiro das pretensões francesas do dia 15 de maio de 1895 na Vila do Espírito Santo do Amapá, e que, devido aos seus atos de coragem e bravura, fora reconhecido pelo Governo brasileiro como herói nacional e defensor da pátria. (Viana; Silva, 2012, p. 69)

A passagem revela sua preocupação em mostrar como Veiga Cabral passou a ser imaginado socialmente após o confronto com as tropas francesas no ano de 1895. Após as definições favoráveis à causa brasileira em Berna, na Suíça, a República Brasileira tentou construir uma imagem de herói para Veiga Cabral. Como se reafirma neste trecho:

A ideia de imaginário social que se construiu ao longo do tempo no Amapá, desde a reação da população da Vila do Espírito Santo do Amapá à elevação de Cabralzinho a herói, fora uma forma de criar na sociedade amapaense o 
sentimento de nacionalismo, que a partir da assinatura do Laudo de Berna, em 1900, os sujeitos históricos da antiga área contestada pela França e por Brasil passaram a ser considerados brasileiros de direito e de fato, assim, fortalecendo a construção de uma nova sociedade amapaense feita pela sua própria história. (Viana; Silva, 2012, p. 76)

Dessa forma, os pesquisadores pretendem estabelecer de forma clara que Veiga Cabral não foi um herói espontâneo criado no seio do corpo social, mas sim um fragmento de memória construída e estimulada pelo governo brasileiro desde o Rio de Janeiro. Mesmo assim, não há impedimento para que Viana e Silva (2012, p. 89) reconheçam Veiga Cabral como personagem histórico relevante para a história brasileira, pois conseguiu agir com todas as características que se esperam de um herói, ou seja, com liderança, carisma, perseverança etc.

Em outra narrativa histórica acadêmica aparecem claramente essas tendências à valorização de personagens marginalizados ao se fazer uma releitura dos acontecimentos na Questão do Amapá. Debora B. Alves (2015) apresenta os negros Bonis, ex-escravos da região do Suriname que pretendiam se instalar próximo à colônia francesa criada em 1836. Como havia medo das elites regionais diante da possibilidade da cooperação entre esses negros e os negros franceses, o poder local se utilizou de força e repressão para expulsá-los. A autora comenta essa ação francesa do poder local:

Com a determinação dos Bonis de permanecerem na região, os franceses resolveram tomar medidas mais drásticas. Em julho de 1841, foi organizada uma expedição militar que atacou o grupo que se achava localizado um pouco acima do forte de Cafésoca. O chefe dos Bonis foi morto, dois outros foram feridos, uma mulher foi capturada e os demais conseguiram fugir. Depois disso, os Bonis desistiram de se instalar no Oiapoque... (Alves, 2015, p. 12)

A expulsão dos Bonis da região da colônia francesa ratifica a ideia da autora de estudar a população local, pois revela os interesses e atuações no espaço temporal pesquisado. Essa ação da pesquisadora mostra a sua disposição em criar uma narrativa histórica acadêmica que assegure espaço para os diversos grupos sociais - mostre a tradicional participação dos agentes políticos nacionais e locais, mas também enfatize a participação de grupos marginais como os Bonis. Ela evita a continuidade de escritos estereotipados como tradicionalmente se 
convencionou fazer na história, e, ao mesmo tempo, pretende dar visibilidade aos vários grupos que atuaram no espaço franco-brasileiro.

Em uma segunda narrativa, Debora B. Alves analisa o papel histórico de Remígio Antonio, capitão principal dos índios entre o início da década de 1850 e meados dos anos 1860. Diz ela:

O objetivo deste trabalho é recuperar um sujeito histórico completamente esquecido pela historiografia sobre o território litigioso entre o Brasil e a França, embora seu nome esteja presente na documentação oficial tanto francesa quanto brasileira: Remígio Antonio. A meu ver, a história deste protagonista nos possibilita entender as redes sociais, políticas e econômicas construídas no Amapá entre 1850 e 1866 em torno de sua pessoa, assim como as relações de comunidade, da qual era o Principal, com o governo imperial brasileiro e colonial francês através de sua intermediação. Suponho que seu papel na região como capitão Principal ou chefe escolhido pelos moradores, na sua maioria outlaws, tenha sido primordial para manter a comunidade, até o início da década de 1880, relativamente independente dos jogos de interesse regional e nacional nessa área amazônica. Não pretende escrever o que poderia ser considerado uma biografia de Remígio Antonio, já que os dados disponíveis são muito fragmentados, mas espero dar vida a este personagem e a muitos outros considerados fora da lei pelas sociedades estabelecidas no Pará e na Guiana Francesa. (Alves, 2017, p. 1, grifo nosso)

A pesquisadora pretende revelar um personagem histórico relegado ao Esquecimento pelos estudos históricos sobre o contestado franco-brasileiro. Como estudado, o fenômeno do Esquecimento é utilizado para mostrar os conflitos de memórias que dada sociedade esteja fomentado acerca de um evento histórico. Já inicialmente a autora revela uma característica da estrutura de sua narrativa, isto é, não deixar que o Esquecimento provoque amnésia histórica dos personagens históricos que viveram na região do conflito franco-brasileiro.

\section{As NARRATIVAS HISTÓRICAS DIDÁTICAS}

No ano de 2001, o autor Fernando dos Santos publicou um livro sobre a História do Amapá com clara alusão ao público-alvo, os alunos do Ensino 
Fundamental da Educação Básica. No prefácio, intitulado "Seção aos Estudantes", ele aponta o objetivo da obra:

Com esta obra é nosso propósito proporcionar-lhe informações sucintas sobre a História do Amapá desde o período colonial até os dias atuais. Todos os acontecimentos relevantes foram destacados, e como você comprovará, os analisamos com seus similares nacionais. Também é meta nossa que o conhecimento substancial da nossa história, em suas diversas fases, contribua de forma positiva na formação de seu senso crítico, levando-o a conclusões coerentes e acertadas sobre nossa realidade política, econômica e social. (Santos, 2001, p. 2)

Além do público-alvo, o autor elege como finalidade em primeiro lugar o conhecimento sintetizado da história do Amapá, e em segundo, a "formação do senso crítico" no aluno.

A narrativa didática de Fernando dos Santos tem características próprias em relação a outros suportes. A primeira consiste em não seguir o fenômeno do Silêncio e do Esquecimento presente em livros didáticos (Pitágoras, UNO e Ática), quando lança luz sobre os acontecimentos da Questão do Amapá que não aparecem nos suportes citados, isto é, são omitidos em sua estrutura (sumário e curricular). Tais livros didáticos trabalham a Primeira República, mas omitem os assuntos de definições fronteiriças, como o Amapá-Guiana Francesa, Acre-Bolívia etc. Seu texto tem linguagem concisa e, o mais importante, busca narrar os acontecimentos no modelo clássico ou oficial, sobressaindo uma série de datas da História do Amapá. A segunda característica é a escolha do período em que estuda a Questão do Amapá, fixada na seção "Agravamento da Questão Fronteiriça” - o autor inicia pelo espaço-tempo do século XVIII. Nos moldes de narrativas históricas oficiais, o autor se concentra nos Tratados de Limites assinados entre as Coroas portuguesa e francesa:

A França, em 10 de agosto de 1797, voltou a reclamar a posse de parte das terras situadas entre os rios Araguari e Oiapoque. O imperador Napoleão Bonaparte, sustentado pelo poderio militar francês, determinou o limite entre o Brasil e a Guiana, pelo rio Calçoene. A ambição imperialista francesa não parou por aí. Anulou os Tratados anteriores e impôs outros, estabelecendo em 1801, o rio Araguari como o limite entre as duas nações. (Santos, 2001, p. 26) 
A constante citação de datas, nome de personagens históricos oficiais e tratados mostra que o eixo das suas narrações apresenta certas contradições em relação à proposta inicial de negar o Silêncio e o Esquecimento. Esse fenômeno marcado pela Memória aponta que existem conflitos e disputas memoriais no seio da sociedade, de forma grosseira, entre a Memória coletiva oficial e a Memória esquecida. Ora, quando o autor elenca datas, nome de personagens históricos oficiais e limites, impossibilita apresentar outras narrações e outros personagens históricos; logo, de alguma forma a sua narração produz esquecimento de grupos sociais marginalizados, como desertores, mocambeiros, escravos fugidos, indígenas, regatões, mineradores etc. A terceira característica é a sua opção pela narrativa com elogio velado à posição brasileira contra os franceses. No início do capítulo V, "Ameaça à integridade nacional”, seção "Ação Aventureira”, diz que a experiência da República do Cunani foi uma estratégia "ilegal" e "imoral”. Além disso, utiliza alcunhas depreciativas ao citar a posição francesa, como o termo "republiqueta". Para demonstrar como a sua narrativa pretende escolher um lado na questão, o autor descreve assim a República do Cunani:

A República do Cunani, como ficou conhecida a ilegal e imoral aventura, tinha sua sede em Paris. Durante sua existência, criou-se bandeira, cunharam-se moedas e concederam-se títulos honoríficos, denominados Ordem de Cavaleiro Estrela de Cunani, mediante pagamento, proporcionando elevados lucros ao idealizador da republiqueta, que se tornou seu presidente vitalício. (Santos, 2001, p. 37, grifos nossos)

Salvo o grifo "Ordem de Cavaleiro Estrela de Cunani” feito pelo autor, os demais são adjetivos pejorativos analisados por esta pesquisa. Sua narrativa histórica didática é profundamente eivada de posicionamento favorável à causa brasileira em Oiapoque em fins do século XIX.

O livro didático História, $5^{\circ}$ ano: Ensino Fundamental, livro 1, da Editora Educacional, usado para o segmento do Ensino Fundamental I, especificamente $\mathrm{o} 5^{\circ}$ ano, é produzido pela Editora Educacional. Sediada em Belo Horizonte, onde cria materiais didáticos específicos de aprendizagem para cada segmento educacional, produz os livros didáticos da Rede Pitágoras, atuante no mercado educacional há cerca de 50 anos. Os livros são produzidos anualmente e trazem firma autoral. O livro didático $\mathrm{n}^{\circ} 1$ de 2017 tem quatro capítulos com os 
seguintes títulos: 1) rompendo os laços com Portugal: a independência do Brasil; 2) a formação do território brasileiro; 3) mudanças políticas: da monarquia à república; e 4) transformações socioeconômicas no Brasil Império. $\mathrm{O}$ capítulo escolhido para análise que é o segundo, onde se encontra o espaço-tempo da Questão do Amapá. No Sumário, esse capítulo se organiza assim:

Será que o Brasil sempre foi desse tamanho?

Nossa primeira fronteira: o Tratado de Tordesilhas

A ocupação da área colonial portuguesa na América

A expansão territorial na América portuguesa

Definindo limites e fronteiras

A ocupação do território brasileiro

(Moraes; Oliva, 2017, p. 6)

Mesmo com o item sobre as definições fronteiriças brasileiras, a Questão do Amapá não ganha o destaque merecido, pois há apenas uma breve menção à existência do conflito franco-brasileiro. Portanto, o Silêncio e o Esquecimento se tornam evidentes nesse suporte didático.

O segundo livro didático, História, $9^{\circ}$ ano: Ensino Fundamental 2, livro 1, da Editora Educacional, usado por uma escola privada em 2017 na cidade de Santana para o segmento do Ensino Fundamental II, é produzido anualmente, tem autoria de Magalhães e Hermeto (2015) e orienta os professores no uso do material didático no Ensino de História. Na seção "Apresentação do componente curricular para o segmento", consta sobre o Ensino de História:

Dessa forma, fica perceptível que neste livro, os conteúdos são tratados de forma sequencial e integrada, procurando articular os contextos mundial e brasileiro e enfatizar aspectos relativos à realidade nacional, em conexão com os acontecimentos relativos à história do mundo ocidental. Sabemos que a história do Brasil, mesmo no século XX, não segue pari passu as histórias europeia e norte-americana. Por isso, procuramos dar um tratamento específico à nossa história sem a necessidade, às vezes, de buscar explicação externa para os acontecimentos ocorridos no nosso país durante a trajetória focada por este estudo. (Magalhães; Hermeto, 2015, p. 5) 
Os autores afirmam claramente que a história nacional deve ser enfatizada perante a história mundial. Não há uma preocupação na utilização da história local, como pedem os documentos oficiais sobre o Ensino de História. Logo, se não existe essa preocupação, a identidade local dos alunos se torna prejudicada em termos de conteúdo, cabendo ao professor romper com essa lógica nas suas atuações em sala de aula.

Essa ênfase se repete ao longo do livro, pois no capítulo referente à Primeira República não existe nenhuma referência à Questão do Amapá, como se os incidentes com Cabralzinho em 1895 e o Laudo do Tribunal de Berna em 1900, dando ganho de causa ao Brasil sobre a França, não tivessem ocorrido. Em verdade, são silenciados e esquecidos de forma proposital, como aparecem na apresentação do suporte didático.

Por fim, outra narrativa histórica didática é o livro História em Movimento, utilizado pela Escola Estadual Augusto Antunes entre 2015 a 2017 na cidade de Santana para o segmento do Ensino Médio, especificamente na $3^{\text {a }}$ série. Firmado com a autoria de Azevedo e Seriacopi (2013), é distribuído pela Editora Ática, referência na venda de livros didáticos e paradidáticos, com mais de 2 mil títulos de obras em áreas como Literatura, Romance, Gramática e Caligrafia. Recentemente, em 2016, ocorreu uma associação entre a editoras Ática e Scipione, quando ambas passaram a fazer parte do portfólio de editoras da Somos Educação, antiga Abril Educação. Recentemente, a Ática apresentou um balanço de seus lucros com o Plano Nacional do Livro Didático (PNLD) 2016, aproximadamente em R\$ 326 milhões. Não é um acaso que as Editoras Ática e Scipione priorizem o mercado de livro didático em suas vendas.

A obra de Azevedo e Seriacopi organiza-se em quatro unidades, e esta pesquisa concentra sua análise na "Unidade 1 - Ciência e Tecnologia", dividida em 5 capítulos que abordam os seguintes temas:

Capítulo 1 - O mundo em transformações 1. A Belle Époque 2. A democratização da Europa.

Capítulo 2 - A Primeira Guerra Mundial 1. A paz armada 2. Brutalidade sem precedentes.

Capítulo 3 - A Revolução Russa 1. A Rússia no início do século XX 2. A revolução de 1905 3. A Revolução de Fevereiro de 1917 4. A Revolução de Outubro de 1917 5. Comunismo na Rússia. 
Capitulo 4 - O Brasil chega ao século XX 1. Ascensão e queda da borracha 2. A expansão industrial no início do século XX 3. Os imigrantes e a formação do povo brasileiro 4. A discriminação étnica 5. A urbanização excludente das cidades.

Capitulo 5 - Primeiros tempos republicanos 1 . Nas mãos da elite 2. As oligarquias no poder 3. 3. Movimentos messiânicos 4. A delimitação de fronteiras. Fechando a unidade.

(Azevedo; Seriacopi, 2013, p. 4, grifos nossos)

Os capítulos grifados, $4^{\circ}$ e $5^{\circ}$, são aqueles responsáveis temporalmente pela Questão do Amapá. Em outras palavras, é nesses espaços narrativos que se observa quais características o evento histórico local possui. Ademais, destaca-se a seção "Fechando Unidade", na qual são propostas atividades discursivas sobre o tema geral da unidade 1, no caso, Ciência e Tecnologia. Nesse espaço, antes das perguntas, surgem documentos para que o aluno utilize sua habilidade e competência de leitura de fontes documentais históricas. Os documentos apresentam relação com o título da unidade e, também, com os seus capítulos.

No Capítulo 4, "O Brasil chega ao século XX”, dá-se atenção aos seguintes temas: no $1^{\circ}$ tópico aparece o desenvolvimento do ciclo econômico da borracha em seu auge e decadência; no $2^{\circ}$ está o desenrolar da indústria no começo do século XX; no $3^{\circ}$ se encontra a análise da imigração e a sua relação com a formação do povo brasileiro; no $4^{\circ}$ está o debate sobre discriminação de etnias no país no espaço-tempo da primeira metade do século XX; e no $5^{\circ}$ e último aparece o processo de urbanização seletivo no Brasil. Em todos os assuntos desses tópicos não existe menção ao estado do Amapá, no máximo ao eixo nevrálgico amazônico, Belém do Pará. Assim, a Questão do Amapá não é tratada nesse capítulo, o que aponta características de Silêncio e Esquecimento. Pode-se afirmar que há uma seletividade de temas sobre a história do Brasil no século XX, com clara centralização na história do eixo Sul-Sudeste do país. Os autores buscaram em sua narrativa histórica didática o apagamento de Memórias, como diz Ricoeur (2007), para que fossem esquecidas aquelas histórias não importantes para a Memória Oficial do Estado brasileiro.

No Capítulo 5, entre as páginas 52 e 66, "Primeiros tempos republicanos", o trabalho focaliza os seguintes assuntos: no $1^{\circ}$ tópico encontra-se a articulação das elites brasileiras para a sua manutenção como protagonistas na República; 
o $2^{\circ}$ analisa a política dos governadores conhecida como a República oligárquica; no $3^{\circ}$ surgem os movimentos de caráter messiânico durante a Primeira República (1889-1930); e no $4^{\circ}$ e último tópico abordam-se as questões de limites brasileiras do início do século XX. Diferentemente do que se viu no Capítulo 4, o tópico 4 sobre o processo fronteiriço no país teoricamente deveria ser o responsável por falar dos diversos acordos e tratados diplomáticos feitos pelo Brasil no período. Entretanto, o foco recai na Questão mais famosa para os livros didáticos e a historiografia, o Acre. Portanto, mais uma vez, assim como nos outros livros didáticos aqui analisados, de Magalhães e Hermeto (2015) e Moraes e Oliva (2017), não há preocupação com o tema desta pesquisa. Isso prejudica os alunos do Amapá, já que não podem conhecer mais sobre a história do seu próprio estado.

\section{CONSIDERAÇÕES FINAIS}

O presente trabalho apresentou as narrativas históricas comparadas sobre a Questão do Amapá, pretendendo estabelecer um diálogo entre a área de Ensino de História e a Epistemologia.

Primeiramente, debateram-se as narrativas históricas acadêmicas sobre a Questão do Amapá. Diante da quantidade elevada de textos sobre o tema, fez-se a escolha de análise com leituras mais hodiernas, a partir do início do século XXI. Inicialmente, acreditava-se que todas as narrativas históricas sobre o tema deveriam, de alguma maneira, apresentar uma das quatro características analisadas, isto é, os fenômenos de Arquétipo, Estereótipo, Silêncio e Esquecimento. À medida que se fizeram as leituras, como estratégia prévia para o uso da comparação, chegou-se às seguintes conclusões.

As leituras históricas mais recentes caracterizam-se por negar o modelo teórico e explicativo deste trabalho. Não foram encontrados sintomas de valorização de heróis e mitos, muito menos de exclusão de grupos sociais. Ao contrário, a maioria das narrações acadêmicas valoriza personagens históricos excluídos pela historiografia do século XIX, especialmente os grupos sociais de escravos, indígenas, ex-escravos, desertores militares e garimpeiros. $\mathrm{O}$ foco diminuído sobre mitos e heróis, como Rio Branco e Veiga Cabral, permitiu o surgimento de personagens históricos esquecidos e silenciados em outras narrativas históricas acadêmicas, como Remígio Antonio, capitão principal dos 
índios na região do Oiapoque na segunda metade do século XIX. Essas narrativas históricas acadêmicas mais recentes, portanto, são repensadas e reconsideradas nas análises, o que sugere novas conclusões.

Em primeiro lugar, as narrativas históricas acadêmicas são plurais, pois dependem necessariamente da opção dos autores. Eles escolhem os personagens a focalizar, o enredo, o espaço-tempo da pesquisa e as suas conclusões. No século XX, era comum encontrar autores que optavam por linguagens arquetipadas, estereotipadas, silenciadas e esquecidas. Já nas duas últimas décadas, essas características não dão conta de explicar o fenômeno histórico ocorrido na região entre os rios Oiapoque e Araguari. Em segundo lugar, as narrativas históricas acadêmicas são heterodoxas, por sua capacidade de alteração constante. Elas não são estanques e cristalizadas em características teóricas pré-selecionadas, possuem certa dose de porosidade teórica. As suas linguagens históricas são, portanto, instáveis com o desenrolar do tempo. Elas se modificam com e no tempo, e assim atribuem novos olhares para a Questão do Amapá.

O pesquisador acadêmico reorienta a sua linguagem à proporção que reconhece novas fontes ou reinterpreta as antigas. Ele dá voz a personagens, enredos, hipóteses históricas não focalizadas em outros momentos. Sendo assim, pode-se concluir que as narrativas históricas acadêmicas são marcadas pela constante alteração em seus pontos cruciais de linguagem. Em outras palavras, percebe-se que elas se comportam - em sua maioria - de forma a negar o modelo teórico da pesquisa acadêmica, isto é, não pretendem apresentar linguagens arquetipadas, estereotipadas, silenciadas e esquecidas.

Por fim, apresentaram-se aqui as narrativas históricas didáticas sobre a Questão do Amapá. Optou-se pela análise de dois tipos de livros paradidáticos, chegando a possíveis conclusões sobre tais suportes. Em primeiro lugar, em algumas leituras históricas perceberam-se as corriqueiras características de Arquétipo e Estereótipo. Essas narrativas históricas paradidáticas citam com frequência os heróis e mitos do evento histórico, como Rio Branco e Cabralzinho. Além disso, dão voz aos grupos sociais dos diplomatas e militares, evitando assim falar na diversidade social existente na região entre os rios Araguari e Oiapoque. Essas leituras confirmam, portanto, a hipótese geral do artigo ao se caracterizarem com alguma das quatro características analisadas 
ao longo do trabalho. No caso específico, essas leituras produzem a fenomenologia de dois conceitos-chaves, que são chamados de Arquétipo e Estereótipo.

\section{REFERÊNCIAS}

ALVES, Debora Bendocchi. Releitura dos acontecimentos na fronteira Grão-ParáGuiana Francesa entre 1835 e 1841. In: SIMPÓSIO NACIONAL DE HISTÓRIA, 28., 2015, Florianópolis, SC. Anais... Florianópolis: Anpuh, 2015. p. 1-16. Disponível em: http://www.snh2015.anpuh.org/resources/anais/39/1433185806_ ARQUIVO_Releituradosac ontecimentosANPUH2015corrigido3eformatado.pdf. Acesso em: 29 out. 2017.

ALVES, Debora Bendocchi. Remígio Antonio, Capitão Principal dos Índios do Amapá: Contestado Franco-Brasileiro, 1850-1866. KLA Working Paper Series, Kompetenznetz Lateinamerika - Ethnicity, Citizenship, Belonging, n. 19, p. 1-63, 2017.

AZEVEDO, Gislane; SERIACOPI, Reinaldo. História em movimento 3 - do século XIX aos dias de hoje. São Paulo: Ática, 2013.

BRASIL. Base Nacional Comum Curricular - terceira versão. Brasília: MEC, 2017. Disponível em: http://www.observatoriodoensinomedio.ufpr.br/wp-content/uploads/2017/04/BNCC-Documento-Final.pdf. Acesso em: 17 abr. 2017.

BITTENCOURT, Circe. O saber histórico em sala de aula. 9. ed. São Paulo: Contexto, 2004.

BRITO, Danilo L. de; BONA, Fabiano Dalla. Sobre a noção de estereótipo e as imagens do Brasil no exterior. Revista Graphos, João Pessoa, v. 16, n. 2, p. 15-28, 2014. Disponível em: http://www.periodicos.ufpb.br/ojs/index.php/graphos/article/ view/23725. Acesso em: 3 set. 2018.

CARDOSO, Francinete. Entre conflitos, negociações e representações: o Contestado Franco-Brasileiro na última década do século XIX. Belém: Associação de Universidades Amazônicas, Universidade Federal do Pará, Núcleo de Altos Estudos Amazônicos, 2008.

CARVALHO, José. A formação das almas: o imaginário da República no Brasil. São Paulo: Companhia das Letras, 1990.

CHEVAllaRD, Yves. La Transposición Didáctica. 3. ed. 2. reimp. Buenos Aires: Aique, 2005.

DETIENNE, Marcel. Comparar lo incomparable. Barcelona: Penínsulas, 2000. Disponível em: https://www.academia.edu/6821817/Marcel_Detienne__ Compara_lo_incomparable. Acesso em: 22 maio 2018. 
GRANGER, Stéphane. O contestado franco-brasileiro: desafios e consequências de um conflito esquecido entre a França e o Brasil na Amazônia. Revista Canteira, v. 17, p. 21-39, jul./dez. 2012. Disponível em: http://www.historia.uff.br/cantareira/ $\mathrm{v} 3 /$ ? $\mathrm{p}=57$. Acesso em: 7 set. 2018.

HARTOG, François. Regimes de Historicidade: presentismo e experiências do tempo. Belo Horizonte: Autêntica, 2014.

HULSMAN, Lodewijk; GUZMÁN, Decio. Swaerooch: o comércio holandês com índios no Amapá (1600-1615). Revista Estudos Amazônicos, v. 6, n. 1, p. 178-202, 2011. Disponível em: http://www.ufpa.br/pphist/estudosamazonicos/arquivos/artigos/1\%20-\%20VI\%20-\%208\%20-\%202011\%20-\%20Lodewijk_Hulsman.pdf. Acesso em: 2 nov. 2018.

JUNG, Carl G. Os arquétipos e o inconsciente coletivo. Petrópolis, RJ: Vozes, 2000.

MAGALHÃES, Gustavo; HERMETO, Mirian. História, $9^{\circ}$ ano: ensino fundamental 2. Belo Horizonte: Ed. Educacional, 2015.

MORAES, Carla; OLIVA, Rejane. História, $5^{\circ}$ ano: ensino fundamental, livro 1. Belo Horizonte: Ed. Educacional, 2017.

POLLAK, Michael. Memória, esquecimento, silêncio. Estudos históricos, Rio de Janeiro, v. 2, n. 3, p. 3-15, 1989.

QUEIROZ, Jonas M. Anotações às margens da história quilombolas e republicanos nas origens do Amapá. In: QUEIROZ, Jonas M.; COELHO, Mauro. Amazônia: modernização e conflito (séculos XVIII e XIX). Belém: UFPA/NAEA, 2001. p. 119-155.

RAMOS, Sebastian; LICORI, Elaine; UTZIG, Antonia. A visão discriminatória e estereotipada sobre o negro no contexto escolar. In: CONEDU, II, 2015, Campina Grande. Anais... Campina Grande: Realize, 2015. p. 1-12. Disponível em: http:// www.editorarealize.com.br/revistas/conedu/trabalhos/TRABALHO_EV045_ MD1_SA14_ID7916_08092015173245.pdf. Acesso em: 13 jan. 2019.

RICOEUR, Paul. A memória, a história, o esquecimento. [1913]. Trad. Alain François [et al.]. Campinas: Ed. Unicamp, 2007.

RÜSEN, Jörn. Experiência, interpretação, orientação: as três dimensões da aprendizagem histórica. In: SCHMIDT, Maria Auxiliadora; BARCA, Isabel; MARTINS, Estevan de R. (org.). Jörn Rüsen e o Ensino de História. Curitiba: Editora da UFPR, 2011. p. 79-91.

SANTOS, Fernando. História do Amapá. 6. ed. Macapá: Valcán, 2001.

SCHNEIDER, Sérgio; SCHMITT, Cláudia. O uso do método comparativo nas Ciências Sociais. Cadernos de Sociologia, Porto Alegre, v. 9, p. 49-87, 1998. Disponível em: https://www.academia.edu/5815441/O_uso_do_m\%C3\%A9todo_ comparativo_nas_ci\%C3\%AAncias_sociais. Acesso em: 9 set. 2018. 
SCHWARCZ, Lilia M. As barbas do imperador: D. Pedro II, um monarca nos trópicos. São Paulo: Companhia das Letras, 1998.

THEML, Neyde; BUSTAMANTE, Regina. História comparada: olhares plurais. Revista de História Comparada, Rio de Janeiro, v. 1, n. 1, p. 1-23, jun. 2007. Disponível em: https://revistas.ufrj.br/index.php/RevistaHistoriaComparada/article/view/146. Acesso em: 3 set. 2018.

VIANA, Jonathan; SILVA, Diovani. Cabralzinho: a construção do mito de um herói inventado na sociedade amapaense. Salto, SP: Schoba, 2012.

ZASLAVSKY, Susana. História comparada em aula de história: qual, por que e como trabalhar? In: BARROSO, Vera et al. Ensino de História: desafios contemporâneos. Porto Alegre: EST: EXCLAMAÇÃO: ANPUH/RS, 2010. p. 231-246.

\section{NOTAS}

${ }^{1}$ A transposição didática é o trabalho que transforma o objeto de saber em objeto de aprendizagem, isto é, no caso das narrativas em história, é saber transformar o que é produzido pelo conhecimento histórico em algo realmente efetivo em termos de conhecimento passado ao alunado (ver: CHEVALLARD, 2005).

${ }^{2} \mathrm{O}$ debate sobre a formação de heróis pela Primeira República se localiza nos trabalhos de José Murilo de Carvalho. Ele defende que Tiradentes é a imagem ideal de herói do novo governo instituído, que deseja justificar perante os cidadãos o novo regime (ver: CARVALHO, 1990).

Artigo recebido em 9 de setembro de 2018. Aprovado em 22 de fevereiro de 2019. 